\title{
Effect of maternal renin-angiotensin-aldosterone system activation on social coping strategies and gene expression of oxytocin and vasopressin in the brain of rat offspring in adulthood
}

\author{
Tomáš Senko, Pavel Svitok and Lucia Kršková \\ Department of Animal Physiology and Ethology, Faculty of Natural Sciences, Comenius University in Bratislava, Slovakia
}

\begin{abstract}
The intrauterine condition in which the mammalian foetus develops has an important role in prenatal programming. The aim of this study was to determine the extent to which activation of the maternal renin-angiotensin-aldosterone system (RAAS) could influence social behaviour strategies in offspring via changes in social neurotransmitters in the brain. Pregnant female Wistar rats were implanted with osmotic minipumps which continually released angiotensin II for 14 days at concentration of $2 \mu \mathrm{g} / \mathrm{kg} / \mathrm{h}$. The adult offspring (angiotensin and control groups) underwent a social interaction test. The mRNA expression of vasopressin, oxytocin and the oxytocin receptor in selected brain areas was measured by in situ hybridisation. Prenatal exposure to higher levels of angiotensin II resulted in a strong trend toward decreased total social interaction time and significantly decreased time spent in close proximity and frequency of mutual sniffing. The angiotensin group showed no changes in oxytocin mRNA expression in the hypothalamic paraventricular or supraoptic nuclei, but this group had reduced vasopressin mRNA expression in the same areas. We concluded that maternal activation of RAAS ( via higher levels of angiotensin II) caused inhibition of some socio-cohesive indicators and decreased vasopressinergic activity of offspring. Taken together, these results suggest a reactive rather than proactive social coping strategy.
\end{abstract}

Key words: Renin-angiotensin-aldosterone system — Angiotensin II — Social coping — Prenatal programming

\section{Introduction}

Prenatal programming is a very complex process. During a critical developmental period, a stimulus or insult can alter foetal or neonatal physiological processes, which can have a long-lasting or permanent effect on the brain, behaviour and disease risk (Barker 1998; Bale et al. 2010). The intrauterine conditions in which the mammalian foetus develops has an important role in this process (Barker 1998).

One of the systems, which can be prenatally programmed, is the renin-angiotensin-aldosterone system (RAAS) (Nuyt 2008). The RAAS is an important regulator of the blood pressure and the fluid/electrolyte homeostasis (Zhuo and Li 2011). However, its role in modulating different physi-

Correspondence to: Tomáś Senko, Department of Animal Physiology and Ethology, Faculty of Natural Sciences, Comenius University, Ilkovičova 6, 84215 Bratislava 4, Slovakia

E-mail: senko5@uniba.sk ological/pathological functions has also been described. The components of the RAAS are present in the central nervous system modulating sensory information, emotional and behavioural responses, learning, memory, pain, anxiety and stress (Llorens-cortes and Mendelsohn 2002; Von Bohlen und Halbach and Albrecht 2006; Bali et al. 2014). RAAS is necessary for proper development of the foetus and all the components of this system are expressed in early human development (Schutz et al. 1996).

During pregnancy, the maternal RAAS can be influenced by several external and internal factors (O'Regan et al. 2004; Nogueira et al. 2007; Sykes et al. 2014; Xiao et al. 2014), which can alter the level of the individual components of this system. In humans, angiotensin converting enzyme (ACE) inhibitors and AT1 receptor (AT1R) antagonist are widely used in therapy of hypertension and it is not unique that pregnant women have this medication (Cooper et al. 2006). However, foetal exposure to ACE inhibitors and/or AT1 receptor antagonist has been 
associated with multiple developmental defects or even intrauterine foetal death (Quan 2006; Bullo et al. 2012). On the other hand, very little data has been provided about the effects of increased angiotensin II concentrations during pregnancy on in utero development of the foetus (Svitok et al. 2017).

Foetal adaptations to supraoptimal intrauterine conditions (e.g. chronic variable stress) can lead to changes in the physiological mechanisms associated with coping strategies (Mueller and Bale 2007).

Two stress response patterns have been distinguished based on social stress research in animals and humans proactive (active) and reactive (passive) coping (Henry and Grim 1990; Koolhaas et al. 1999, 2010).

Proactive social coping behaviour with higher sympathetic reactivity has been shown to increase the predisposition for hypertension, atherosclerosis and tachyarrhythmia (Henry and Grim 1990; Hessing et al. 1994; Sgoifo et al. 2005). On the other hand, reactive social coping behaviour is associated with higher parasympathetic tone and reactivity, predisposing the individual to sudden cardiac death due to bradyarhythmia (Koolhaas et al. 1999).

Social stressors play an important role during the mammalian life course (Koolhaas et al. 1997; Sgoifo et al. 2005), and prenatal programing influences the adaptation strategy for this type of stress. The oxytocin (OT) and arginine vasopressin (AVP) neuropeptides are involved in inter-neuronal communication within various areas of the brain to modulate social-emotional behavioural and physiological responses, reflective of the coping style (Holmes et al. 2003; Koolhaas et al. 2010).

Both neuropeptides are produced by magnocellular and parvocellular neurosecretory neurons in the paraventricular (PVN), supraoptical (SPO) and accessory nuclei of the hypothalamus. AVP is also produced by parvocellular cells in the suprachiasmatic nucleus (SCN) (Carter 2007).

Increased vasopressinergic activity in discrete brain regions linked to regulation of stress coping behaviour is associated with increased levels of aggressiveness, and perhaps, a more proactive coping style in general (Bult et al. 1992; Compaan et al. 1992; Aubry et al. 1995; Everts et al. 1997; Koolhaas et al. 2010). On the other hand, increased oxytocinergic activity in these very same neural structures associated with facilitating social attachment, care and relationships (Insel et al. 1998; Heinrichs et al. 2009) and may be implicated in more reactive (passive) coping behaviours (de Boer et al. 2003; Koolhaas et al. 2010).

In the current study, we investigated the extent to which the activation of maternal RAAS ( via prenatally increased angiotensin II) could influence social behaviour strategies in adult offspring via changes in the level of social neurotransmitters in the brain.

\section{Material and Methods}

Our research is part of a larger project focused on the effects of prenatal activation of regulatory mechanisms of blood pressure. The experiment was performed in compliance with the Principles of Laboratory Animal Care issued by the Ethical Committee of Comenius University in Bratislava, Slovak Republic. The experimental design was approved by the State Veterinary and Food Administration of the Slovak Republic.

\section{Animals}

Wistar rats (VELAZ Praha, Czech Republic) were used in this study. The parental generation consisted of nine females and four males. Animals were housed in groups of two or three animals in standard light conditions (12:12 hour light-dark cycle; lights on at 6:00), with an average temperature of $21 \pm$ $2{ }^{\circ} \mathrm{C}$ and $55 \pm 5 \%$ relative humidity. Water and food (standard laboratory chow) were available ad libitum. After an acclimatisation period of 7 days, female rats were divided into two groups: the control group (Ctrl; $n=4)$, and the angiotensin II group (AngII; $n=5$ ). The animals were mated overnight. The ovulatory cycle phase and day 0 of gestation (the presence of spermatozoa in a vaginal smear) were identified according to Gleich and Frohberg (1977).

Osmotic minipumps were implanted on the sixth day of gestation (model 2002, Alzet, Canada), placed subcutaneously on the back of dams in the AngII group, through which angiotensin II ( $1.36 \mathrm{mg} / \mathrm{ml}$ in physiological solution) was continuously released at $2 \mu \mathrm{g} / \mathrm{kg} / \mathrm{h}$ for 14 days. In contrast, an oval object of the same shape and size (sham operation) was implanted into control dams. For the surgery, animals were anesthetised using a solution of ketamine $(135 \mathrm{mg} / \mathrm{ml}$; Nar$\operatorname{ketan}^{\mathrm{TM}} 10$, Chassot GmbH, Germany) and xylazine (18 mg/ $\mathrm{ml}$; Rometar 2\%, Spofa, Czech Republic). The animals were kept under the same conditions as prior to surgery until birth. Following birth, the litters were culled to eight animals per litter (four males and four females). Each dam and litter were housed together in individual cages until weaning at postnatal day 21. After weaning, rats of each gender were housed separately in groups of four animals per cage.

Body weight did not differ between control and AngII dams before, or at the end of pregnancy. Angiotensin II administration had no effects on litter size or birth weight of the offspring. Sex ratio of pups was similar between both groups and the body weight did not differ between groups during the whole course of the experiment. Increased angiotensin II during pregnancy raised blood pressure in the offspring. Treatment also increased aldosterone and decreased plasma renin activity in the offspring (Svitok et al., in press).

Animals were anaesthetised with $\mathrm{CO}_{2}$ and decapitated at postnatal day 79-83. Their brains were immediately removed and placed into frozen medium (Cryomount, Histolab AB, 
Sweden), frozen in dry ice and stored at $-80^{\circ} \mathrm{C}$. Brains from the litters of $4 \mathrm{Ctrl}$ and 5 AngII females (Ctrl $n=20$, males $n=10$, females $n=10$; AngII $n=20$, males $n=10$, females $n=10$ ) were used for in situ hybridisation. The brains of all animals tested in the social interaction test were also evaluated by in situ hybridisation.

\section{Social interaction test}

The social interaction test was adapted from File (1980). At 77 days of age, the offspring (Ctrl: male $n=10$; female $n=10$; AngII: male $n=10$, female $n=10$ ) were tested for their social interaction behaviours with an unknown test partner of the same weight (no more than $10 \mathrm{~g}$ difference), sex and treatment. Pairs were tested in a random order between 14:00 and 15:00. The dimensions of the test box were $33.5 \times 71 \mathrm{~cm}$, with walls $37 \mathrm{~cm}$ high.

Animals were acclimatised the day before testing by singly placing each animal in the test box for 20 minutes. Pairs of animals were placed in diagonally opposite corners of the box. The behaviour of the animals was measured over a period of 5 minutes, which was recorded using a digital camera (DCR-DVD 92 E; Sony, Japan).

The latency until first contact (duration in seconds) and total duration and frequency of socio-cohesive (following, chasing, mutual sniffing, genital investigation, climbing over, crawling under, allogrooming contact, time in close proximity) and socio-aversive (escape, mounting, tail biting) interactions were recorded during the time period from the video.

\section{In situ hybridisation}

The mRNA expression of AVP, OT (neurotransmitters responsible for social activity) in the hypothalamic PVN or SPO nuclei (the site of their synthesis) was measured by in situ hybridisation.

The in situ hybridisation protocol has been previously described elsewhere (Štefánik et al. 2015). Briefly, consecutive frozen cryostat sections of the rat brain $(14 \mu \mathrm{m})$ were mounted on adhesion slides (SuperFrost ${ }^{\circledR}$ Plus, MenzelGläser, Thermo Fisher Scientific Inc., Germany) for subsequent hybridisation of the chosen mRNAs. A synthetic 41-base oligonucleotide probe with the sequence 5'-GGG CTC AGC GCT CGG AGA AGG CAG ACT CAG GGT CGC AGG CG-3' was used, complementary to nucleotides 906-946 of the rat OT mRNA (GenBank accession number K01701) (Patisaul et al. 2003). For hybridisation of AVP mRNA, a 48-base probe with the sequence 5'-GCA GAA GGC CCC GGC CGG CCC GTC CAG CTG CGT GGC GTT GCT CCG GTC-3' was used (directed against the final 16 amino acids of the glycoprotein that is not shared with OT) (Müller et al. 2000). All sequences were firstly checked for complementarity with non-specific rat RNA using BLAST in the EMBL sequence database. None of the probes recognised different non-specific sequences with sufficient fidelity.

Probes were labelled at the 3 '-end with $\left[a^{-35} \mathrm{~S}\right]$ dATP ( $1200 \mathrm{Ci} / \mathrm{mmol}$; Perkin Elmer Inc., USA) by terminal deoxynucleotidyl transferase (Thermo Fisher Scientific Inc., Canada). Unincorporated radioactivity was removed with Sephadex G-50 micro-columns (GE Healthcare, Little Chalfont, UK). The sections were fixed in $4 \%$ paraformaldehyde in phosphate buffered saline (PBS; $\mathrm{pH}$ 7.4) for 5 minutes, then rinsed twice in PBS, acetylated in a solution containing $0.25 \%$ acetic anhydride in $0.8 \%$ triethanolamine hydrochloride and $0.9 \%$ sodium chloride for 10 minutes. Sections were dehydrated through graded ethanol solutions, delipidated in chloroform for 5 minutes, then dipped in 100 and 95\% ethanol prior to air-drying. Sections were hybridised with the labelled probe in $70 \mu \mathrm{l}$ of hybridisation buffer per slide (50\% formamide, $4 \times$ saline-sodium citrate (SSC) buffer, $1 \times$ Denhardt's solution, $10 \%$ dextran sulphate, $500 \mu \mathrm{g} / \mathrm{ml}$ sheared single-stranded DNA and $250 \mu \mathrm{g} / \mathrm{ml}$ yeast tRNA), which was mixed with $0.1 \mathrm{M}$ dithiothreitol (DTT) and the purified radiolabelled oligoprobe $(270,659 \mathrm{cpm} / \mu \mathrm{l}$ for OT and $186,625 \mathrm{cpm} / \mu \mathrm{l}$ for AVP) before use. The radiolabeled probe was diluted to a concentration of $2.7 \times 10^{6}$ counts/ $\mathrm{min} / \mathrm{ml}$ (OT and AVP). The slides were incubated in humidified boxes for 18 hours at $41^{\circ} \mathrm{C}$. Post-hybridisation, the slides were processed by washing with $1 \times$ SSC for 5 minutes at room temperature, then in $1 \times \mathrm{SSC}$ for 1 hour at $55^{\circ} \mathrm{C}$, and finally in $1 \times$ SSC for 1 hour at room temperature. Afterwards, the slides were dipped in distilled water then $70 \%$ ethanol, then left to air-dry.

Slides with probes for OT and AVP were exposed to Hyperfilm-Beta-Max (Eastman Kodak Company, Chalonsur-Saône, France) for 48 hours. The film was developed using a developer (LQN) solution then fixed in FOMAFIX (FOMA, Hradec Králové, Czech Republic) solution. After exposure, the slides were stained with cresyl violet to determine the position and shape of the neuronal structures.

Autoradiographs were captured using an optical magnifier and digital camera (AM423X Dino-Eye, Dino-Lite, Taiwan) and corresponding software (Dino Capture 2.0, Dino-Lite, Taiwan), then analysed using ImageJ software (version 1.47i; NIH, USA). The relative density of individual structures was measured for each slide. Optical densities of the SPO and PVN nuclei were determined for OT and AVP. The optical density of signals was bilateral, but was separately evaluated for each section. As an internal standard, the background density adjacent to each structure was captured and subtracted from the density of the region of interest (performed separately for each side). The mean values from the left and right side were obtained from four to six slides per animal. The rat brain atlas (Paxinos and Watson 1998) was used to verify the correct locations. 


\section{Statistical analysis}

All data were analysed using Kolmogorov-Smirnov tests to determine whether they fit a normal distribution. The results were analysed using Statistica version 7.0 software (StatSoft, Inc., Tulsa, OK, USA). Data were analysed by two-way analysis of variance (ANOVA) with the treatment and sex as co-factors. If the interaction was significant $(p<$ 0.05 ), differences in behavioural parameters between control and AngII rats were estimated by Fischer LSD post hoc test.

\section{Results}

\section{Social interaction test}

For the latency until first contact, the two-way ANOVA did not reveal any significant effect of treatment $\left(\mathrm{F}_{(1,36)}=0.001\right.$, $p=0.97)$, sex $\left(\mathrm{F}_{(1,36)}=0.167, p=0.685\right)$ and interaction treatment $v s$. $\operatorname{sex}\left(\mathrm{F}_{(1,36)}=2.124, p=0.154\right)$.

For the total time spent participating in socio-cohesive interactions, the two-way ANOVA did not reveal any significant effect of treatment $\left(\mathrm{F}_{(1,36)}=2.26, p=0.14\right), \operatorname{sex}\left(\mathrm{F}_{(1,36)}\right.$ $=1.62, p=0.21)$ and interaction treatment $v s$. $\operatorname{sex}\left(\mathrm{F}_{(1,36)}=\right.$ $1.717 ; p=0.2$ ). We recognised only a trend towards a lower number of socio-cohesive interactions in AngII females in comparison with Ctrl females ( $p=0.054$; Fig. 1A).

For the time spent in close proximity, the two-way ANOVA revealed significant effect of treatment $\left(\mathrm{F}_{(1,36)}=\right.$ $7.487 ; p<0.05)$, sex $\left(\mathrm{F}_{(1,36)}=6.343 ; p<0.05\right)$, and interaction treatment $v s$. sex $\left(\mathrm{F}_{(1,36)}=10.456 ; p<0.01\right)$. In total, AngII animals spent less time in close proximity compared to Ctrl animals ( $p<0.05$; Fig. 1B). We observed differences between males and females, such that AngII females spent less time in close proximity to the other animal during this test compared to Ctrl females $(p<0.001)$. Ctrl males also spent less time in close proximity than Ctrl females $(p<$ 0.001; Fig. 1B). The two-way ANOVA revealed significant effect of treatment for frequency of sniffing $\left(\mathrm{F}_{(1,36)}=6.1425\right.$; $p<0.05)$. Animals in the AngII group had a lower frequency of sniffing in comparison with Ctrl males ( $p<0.05$; Fig. 1C).

Socio-aversive interactions were not observed for any animal in either the AngII or Ctrl groups.

\section{In situ hybridisation}

The two-way ANOVA revealed significant effect of treatment $\left(\mathrm{F}_{(1,36)}=4.4973 ; p<0.05\right)$ for AVP mRNA expression in PVN. AngII animals had lower AVP mRNA expression compared with Ctrl group (Fig. 2).

Statistical analysis revealed also significant effect of interaction treatment $v$ s. $\operatorname{sex}\left(\mathrm{F}_{(1,36)}=5.637 ; p=0.023\right)$ for AVP mRNA expression in the SPO. AngII males had lower AVP mRNA expression compared with Ctrl males (Fig. 2).

There was no significant effect of treatment and/or sex in OT mRNA expression in either the hypothalamic PVN or SPO between.

\section{Discussion}

In the current study we applied a new model for evaluating developmental programming of cardiovascular disease. This model involved the activation of maternal RAAS via implantation of osmotic minipumps that continually released angiotensin II during most of the gestational period. The
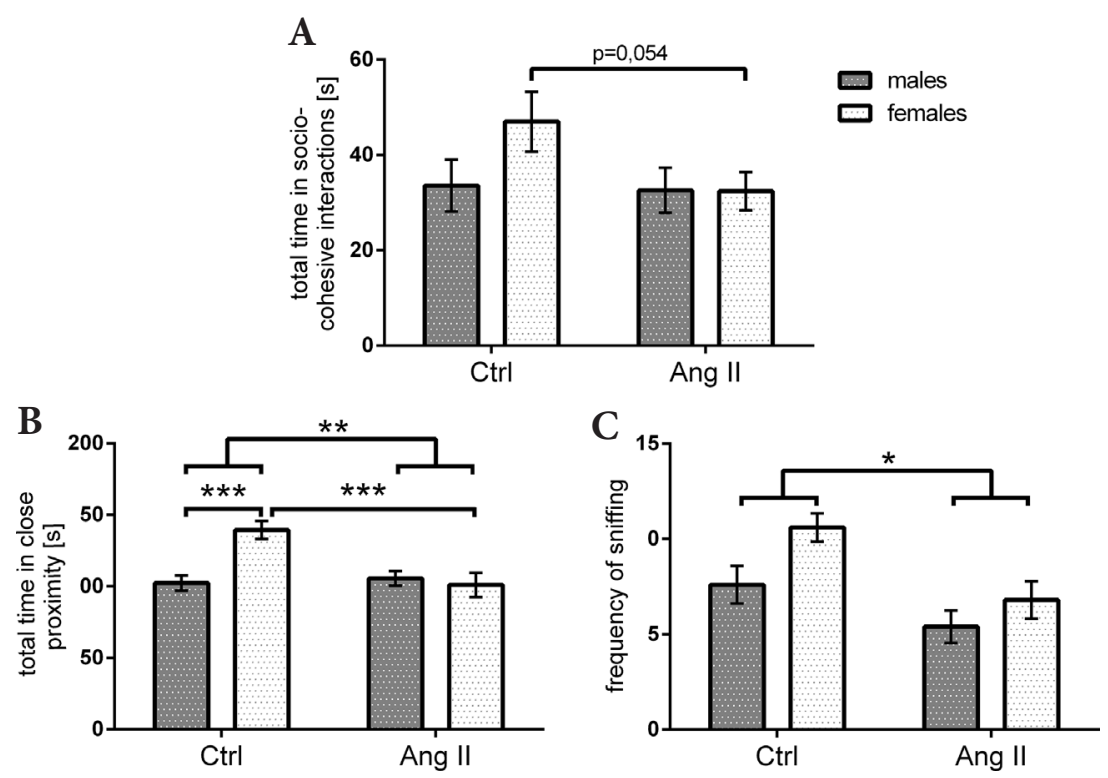

Figure 1. Total time spent participating in socio-cohesive interactions (A), total time spent in close proximity (B), frequency of sniffing $(\mathbf{C})$ in angiotensin (AngII: males $n=10$, females $n=10)$ and control (Ctrl: males $n=10$; females $n=10$ ) groups. Data are means $\pm \mathrm{SEM} ;{ }^{\star} p<0.05,{ }^{* *} p<0.01$, *** $p<0.001$. 

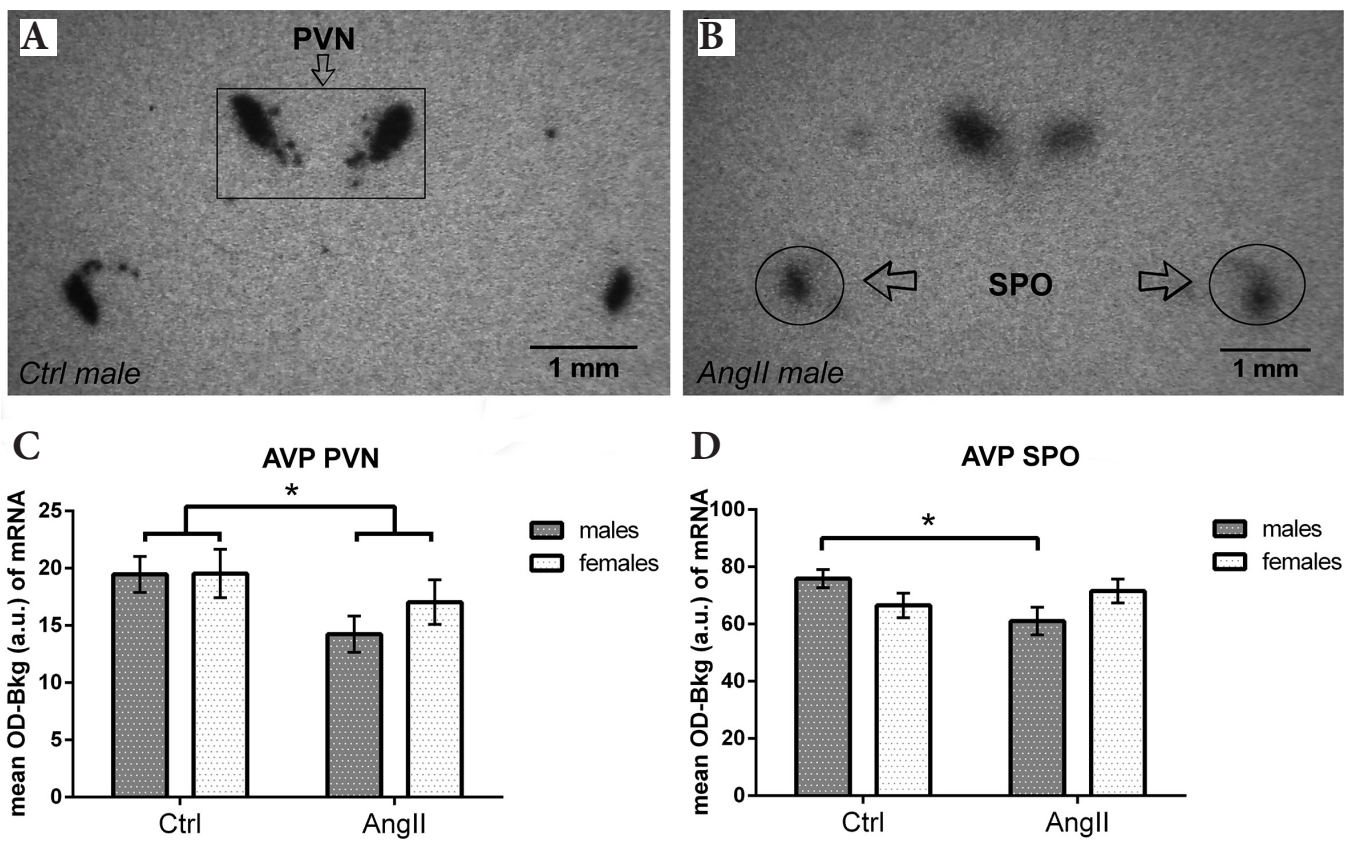

Figure 2. In situ hybridisation for arginine-vasopressin (AVP). Representative in situ photos of AVP mRNA signals in control (Ctrl; A) and angiotensin (AngII; B) group. Comparison of optical density signal for AVP of angiotensin (AngII: males $n=10$, females $n=10$ ) and control (Ctrl: males $n=10$, females $n=10)$ rats in paraventricular (PVN; C) and supraoptical nuclei (SPO; D). Data are means $\pm \mathrm{SEM} ;{ }^{*} p<0.05$.

research presented here is part of a larger project focused on the effects of prenatal activation of regulatory mechanisms of blood pressure, part of which has already been published (Svitok et al. 2017).

We hypothesised that the activation of maternal RAAS (via higher levels of angiotensin II) would be associated with changes in the social coping behaviour of the offspring. There are no studies in the literature that have described the prenatal effects of angiotensin II administration on social behaviour, therefore, we have compared our results with animal models with upregulation (TGR(mRen2)27) and downregulation (TGR(ASrAOGEN6)680) of RAAS.

Studies that have investigated models of downregulated RAAS have reported that rats spent more time in relatively close spatial proximity of the rats without further motor interactions compared with controls in social interaction tests (Voigt et al. 2005; Mayorov 2011) characterized by a transgene-producing antisense RNA against angiotensinogen in the brain, provides an opportunity to study the behavioral effects of angiotensin. While exposed to the elevated plus-maze (EPM). Rats with upregulated RAAS could have a similar effect to the total social interaction observed in rats with downregulated RAAS (Voigt et al. 2005).

Our results showed a trend toward differences in total socio-cohesive interaction. When we focused on individual parameters (time spent in close proximity and frequency of sniffing), we observed similar results to that reported by
Voigt et al. (2005), who observed reduced sniffing in rats with downregulated RAAS. The time spent in close proximity was also found to be decreased in angiotensin II-treated animals. Rats with downregulated RAAS were not different in their latency until first contact behaviour (Voigt et al. 2005), similarly, in our study, prenatal exposure to angiotensin II did not change latency period until first contact.

The present study was based on a prenatal intervention to investigate how blood pressure regulation mechanisms influence programming of social coping strategies. In regard to behaviour, the proactive strategy is not only characterised by higher levels of aggression, dominance and territoriality, but also by a tendency to develop routine-like, rigid, intrinsically driven behaviours (Sgoifo et al. 2005). In contrast, the reactive strategy is characterised by less aggressive, less territorial and subordinated behaviours, in addition to being more flexible and driven by changes in environmental stimuli (Koolhaas et al. 1999; Sgoifo et al. 2005). These two styles of adaptation (coping strategies) also differ in terms of autonomic/neuroendocrine (re)activity. Proactive animals have higher sympathetic activation and lower (re)activity of the HPA axis, whereas reactive animals are parasympathetically driven and have higher HPA axis (re)activity (Koolhaas et al. 1999; Sgoifo et al. 2005).

From our results, maternal RAAS activation (via higher levels of angiotensin II) caused inhibition some aspects of social behaviour in offspring, which we suggest is associated 
with reactive rather than proactive social coping strategies. Our suggestion is supported by higher activation of the HPA axis, that leads to increase of aldosterone levels (Kubzansky and Adler 2010). Aldosterone may induce a wide spectrum of behavioural manifestations of psychological stress (e.g., anxiety, depression) (Hlavacova and Jezova 2008; Hlavacova et al. 2012). This mineralocorticoid plays a key role in modulation of mood through effects on relevant mood-regulating brain areas including nucleus tractus solitarii (Murck et al. 2014). According to Ngarmukos and Grekin (2001), behavioural effect of aldosterone may be mediated by non-genomic mechanism on ionic exchangers or membrane receptors. Aldosterone plays a central role in the regulation of plasma sodium through mineralocorticoid receptors (Bailey et al. 2009). Plasma sodium imbalance can lead to mood disorders and decreased reactivity to psychogenic stressors (Krause et al. 2011; Leshem 2011).

In our study, AngII animals have been reported to have increased plasma aldosterone levels compared to controls (Svitok et al. 2017), also observed in transgenic rats (TGR(mRen2)27) with upregulated RAAS. Aldosterone levels were found to be 10-times higher in rats with upregulated RAAS than in control rats, which supports upregulation of the renin-angiotensin system, as it is well known that angiotensin II stimulates aldosterone synthesis (Ferrario 1983; Zeman et al. 2007).

Furthermore, reactivity of the HPA axis to adrenocorticotropic hormone in transgenic rats is higher compared to other normotensive rat strains (Husková 2006). Higher activation of the HPA axis suggests reactive social coping behaviour.

The two main brain neurotransmitters responsible for social activity in animals are AVP and OT. Generally, increased vasopressinergic activity in discrete brain regions is associated with proactive coping styles, and increased oxytocinergic activity in these very same neural structures is associated with reactive (passive) coping (Koolhaas et al. 2010). In our study, animals in the AngII group did not differ in OT mRNA expression in the hypothalamic PVN or SPO nuclei, however, this group had lower expression of AVP mRNA in the PVN and SPO nuclei of the hypothalamus. These changes again suggest a reactive rather than proactive social coping strategy.

In conclusion, prenatal exposure to higher levels of angiotensin II caused changes in social behaviour, suggestive of a reactive rather than proactive social coping strategy, supported by to altered vasopressinergic activity.

Acknowledgments. The research reported in this paper was supported by grants UK/356/2016; APVV 0291/12, VEGA 2/0166/16; $1 / 0557 / 15 ; 2 / 0107 / 12$. The authors would like to thank Zuzana Panáková, Petra Mikušová and Henrieta Vegešiová for their care about rats and help in collecting some behavioural data.
Conflict of interest: The authors report no conflicts of interest. The authors alone are responsible for the content and writing of the paper.

\section{References}

Aubry J. M., Bartanusz V., Driscoll P., Schulz P., Steimer T., Kiss J. Z. (1995): Corticotropin-releasing factor and vasopressin mRNA levels in Roman high- and low-avoidance rats: Response to open-field exposure. Neuroendocrinology 61, 89-97 https://doi.org/10.1159/000126829

Bailey M. A., Mullins J. J., Kenyon C. J. (2009): Mineralocorticoid and glucocorticoid receptors stimulate epithelial sodium channel activity in a mouse model of cushing syndrome. Hypertension 54, 890-896 https://doi.org/10.1161/HYPERTENSIONAHA.109.134973

Bale T. L., Baram T. Z., Brown A. S., Goldstein J. M., Insel T. R., Mccarthy M. M., Nemeroff C. B., Reyes T. M., Simerly R. B., Susser E. S., Nestler E. J. (2010): Early life programming and neurodevelopmental disorders. Biol. Psychiatry 68, 314-319 https://doi.org/10.1016/j.biopsych.2010.05.028

Bali A., Singh N., Jaggi A. S. (2014): Renin-angiotensin system in pain: Existing in a double life ? J. Renin Angiotensin Aldosterone Syst. 15, 329-340

https://doi.org/10.1177/1470320313503694

Barker D. J. P. (1998): Mothers, Babies, and Disease in Later Life. Churchill Livingstone, London

de Boer S. F., van der Vegt B. J., Koolhaas J. M. (2003): Individual variation in aggression of feral rodent strains: A standard for the genetics of aggression and violence? Behav. Genet. 33, 485-501

https://doi.org/10.1023/A:1025766415159

Bullo M., Tschumi S., Bucher B. S., Bianchetti M. G., Simonetti G. D. (2012): Pregnancy outcome following exposure to angiotensinconverting enzyme inhibitors or angiotensin. Hypertension 60, 444-450

https://doi.org/10.1161/HYPERTENSIONAHA.112.196352

Bult A., van der Zee E. A., Compaan J. C., Lynch C. B. (1992): Differences in the number of arginine-vasopressin-immunoreactive neurons exist in the suprachiasmatic nuclei of house mice selected for differences in nest-building behavior. Brain Res. 578, 335-338

https://doi.org/10.1016/0006-8993(92)90266-C

Carter C. S. (2007): Sex differences in oxytocin and vasopressin: Implications for autism spectrum disorders? Behav. Brain Res. 176, 170-186

https://doi.org/10.1016/j.bbr.2006.08.025

Compaan J. C., Koolhaas J. M., Buijs R. M., Pool C. W., de Ruiter A. J. H., van Oortmerssen G. A. (1992): Vasopressin and the individual differentiation in aggression in male house mice. Ann. New York Acad. Sci. 652, 458-459 https://doi.org/10.1111/j.1749-6632.1992.tb34383.x

Cooper W., Hernandez-Diaz S., Arbogast P., Dudley J., Dyer S., Gideon P., Hall K., Ray W. (2006): Major congenital malformations after first-trimester exposure to ACE inhibitors. N. Engl. J. Med. 354, 2443 https://doi.org/10.1056/NEJMoa055202 
Everts H. G. J., De Ruiter A. J. H., Koolhaas J. M. (1997): Differential lateral septal vasopressin in wild-type rats: correlation with aggression. Horm. Behav. 31, 136-144 https://doi.org/10.1006/hbeh.1997.1375

Ferrario C. M. (1983): Neurogenic actions of angiotensin II. Hypertension 5, V73-79 https://doi.org/10.1161/01.HYP.5.6_Pt_3.V73

File S. E. (1980): The use of social interaction as a method for detecting anxiolytic activity of chlordiazepoxide-like drugs. J. Neurosci. Methods 2, 219-238 https://doi.org/10.1016/0165-0270(80)90012-6

Gleich J., Frohberg H. (1977): An introduction to research techniques. In: Methods in Prenatal Toxicology. Evaluation of Embryotoxic Effects in Experimental Animal. (Ed. D. Neubert), pp. 94-102, PSG Publishing Co, Stuttgart

Heinrichs M., von Dawans B., Domes G. (2009): Oxytocin, vasopressin, and human social behavior. Front. Neuroendocrinol. 30, 548-557 https://doi.org/10.1016/j.yfrne.2009.05.005

Henry J. P., Grim C. E. (1990): Psychosocial mechanisms of primary hypertension. J. Hypertens. 8, 783-793 https://doi.org/10.1097/00004872-199009000-00001

Hessing M. J. C., Hagelsø A. M., Schouten W. G. P., Wiepkema P. R., Van Beek J. A. M. (1994): Individual behavioral and physiological strategies in pigs. Physiol. Behav. 55, 39-46 https://doi.org/10.1016/0031-9384(94)90007-8

Hlavacova N., Jezova D. (2008): Chronic treatment with the mineralocorticoid hormone aldosterone results in increased anxiety-like behavior. Horm. Behav. 54, 90-97 https://doi.org/10.1016/j.yhbeh.2008.02.004

Hlavacova N., Wes P. D., Ondrejcakova M., Flynn M. E., Poundstone P. K., Babic S., Murck H., Jezova D. (2012): Subchronic treatment with aldosterone induces depression-like behaviours and gene expression changes relevant to major depressive disorder. Int. J. Neuropsychopharmacol. 15, 247-265 https://doi.org/10.1017/S1461145711000368

Holmes A., Heilig M., Rupniak N. M. J., Steckler T., Griebel G. (2003): Neuropeptide systems as novel therapeutic targets for depression and anxiety disorders. Trends Pharmacol. Sci. 24, 580-588 https://doi.org/10.1016/j.tips.2003.09.011

Husková Z. (2006): The role of intrarenal renin angiotensin system in the development of hypertension in Ren-2 transgenic rats. Charles University, Prague, $\mathrm{PhD}$ thesis (in Czech)

Insel T. R., Winslow J. T., Wang Z., Young L. J. (1998): Oxytocin, vasopressin, and the neuroendocrine basis of pair bond formation. In: Vasopressin and Oxytocin. (Eds. H. H. Zingg, C. W. Bourque and D. G. Bichet), pp. 215-224, Springer US, Boston https://doi.org/10.1007/978-1-4615-4871-3_28

Koolhaas J. M., De Boer S. F., De Rutter A. J., Meerlo P., Sgoifo A. (1997): Social stress in rats and mice. Acta Physiol. Scand. Suppl. 640, 69-72

Koolhaas J. M., Korte S. M., De Boer S. F., Van Der Vegt B. J., Van Reenen C. G., Hopster H., De Jong I., Ruis M., Blokhuis H. (1999): Coping styles in animals: current status in behavior and stress-physiology. Neurosci. Biobehav. Rev. 23, 925-935 https://doi.org/10.1016/S0149-7634(99)00026-3
Koolhaas J. M., de Boer S. F., Coppens C. M., Buwalda B. (2010): Neuroendocrinology of coping styles: Towards understanding the biology of individual variation. Front. Neuroendocrinol. 31, 307-321 https://doi.org/10.1016/j.yfrne.2010.04.001

Krause E. G., de Kloet A. D., Flak J. N., Smeltzer M. D., Solomon M. B., Evanson N. K., Woods S. C., Sakai R. R., Herman J. P. (2011): Hydration state controls stress responsiveness and social behavior. J. Neurosci. 31, 5470-5476 https://doi.org/10.1523/JNEUROSCI.6078-10.2011

Kubzansky L. D., Adler G. K. (2010): Aldosterone: A forgotten mediator of the relationship between psychological stress and heart disease. Neurosci. Biobehav. Rev. 34, 80-86 https://doi.org/10.1016/j.neubiorev.2009.07.005

Leshem M. (2011): Low dietary sodium is anxiogenic in rats. Physiol. Behav. 103, 453-458 https://doi.org/10.1016/j.physbeh.2011.03.025

Llorens-Cortes C., Mendelsohn F. A. O. (2002): Organisation and functional role of the brain angiotensin system. J. Renin Angiotensin Aldosterone Syst. (Suppl.) 3, 39-48 https://doi.org/10.3317/jraas.2002.029

Mayorov D. N. (2011): Brain angiotensin AT1 receptors as specific regulators of cardiovascular reactivity to acute psychoemotional stress. Clin. Exp. Pharmacol. Physiol. 38, 126-135 https://doi.org/10.1111/j.1440-1681.2010.05469.x

Mueller B. R., Bale T. L. (2007): Early prenatal stress impact on coping strategies and learning performance is sex dependent. Physiol. Behav. 91, 55-65 https://doi.org/10.1016/j.physbeh.2007.01.017

Müller M. B., Landgraf R., Preil J., Sillaber I., Kresse A. E., Keck M. E., Zimmermann S., Holsboer F., Wurst W. (2000): Selective activation of the hypothalamic vasopressinergic system in mice deficient for the corticotropin-releasing hormone receptor 1 is dependent on glucocorticoids. Endocrinology 141, 4262-4269 https://doi.org/10.1210/endo.141.11.7767

Murck H., Büttner M., Kircher T., Konrad C. (2014): Genetic, molecular and clinical determinants for the involvement of aldosterone and its receptors in major depression. Nephron Physiol. 128, 17-25

https://doi.org/10.1159/000368265

Ngarmukos C., Grekin R. (2001): Nontraditional aspects of aldosterone physiology. Am. J. Physiol. Endocrinol. Metab. 281, E1122-1127

Nogueira A. I., Souza Santos R. A., Simoes E Silva A. C., Cabral A. C., Vieira R. L., Drumond T. C., Machado L. J., Freire C. M., Ribeiro-Oliveira A. J. (2007): The pregnancy-induced increase of plasma angiotensin-(1-7) is blunted in gestational diabetes. Regul. Pept. 141, 55-60 https://doi.org/10.1016/j.regpep.2006.12.014

Nuyt A. M. (2008): Mechanisms underlying developmental programming of elevated blood pressure and vascular dysfunction : evidence from human studies and experimental animal models. Clin. Sci. (Lond) 114, 1-17 https://doi.org/10.1042/CS20070113

O’Regan D., Kenyon C. J., Seckl J. R., Holmes M. C. (2004): Glucocorticoid exposure in late gestation in the rat permanently programs gender-specific differences in adult cardiovascular 
and metabolic physiology. Am. J. Physiol. Endocrinol. Metab. 287, 863-870 https://doi.org/10.1152/ajpendo.00137.2004

Patisaul H. B., Scordalakes Ã. E. M., Young L. J. Ã., Rissman E. F. (2003): Oxytocin, but not oxytocin receptor, is regulated by oestrogen receptor beta in the female mouse hypothalamus. J. Neuroendocrinol. 15, 787-793 https://doi.org/10.1046/j.1365-2826.2003.01061.x

Paxinos G., Watson C. (1998): The Rat Brain in Stereotaxic Coordinates. Academic Press, Cambridge, Massachusetts

Quan A. (2006): Fetopathy associated with exposure to angiotensin converting enzyme inhibitors and angiotensin receptor antagonists. Early Hum. Dev. 82, 23-28 https://doi.org/10.1016/j.earlhumdev.2005.11.001

Schutz S., Moullec J. Le, Corvol P., Gasc J. (1996): Early expression of all the components of the renin-angiotensin-system in human development. Am. J. Pathol. 149, 2067-2079

Sgoifo A., Costoli T., Meerlo P., Buwalda B., Pico M. A., Boer S. De, Musso E., Koolhaas J. (2005): Individual differences in cardiovascular response to social challenge. Neurosci. Biobehav. Rev. 29, 59-66 https://doi.org/10.1016/j.neubiorev.2004.07.001

Štefánik P., Olexová L., Kršková L. (2015): Pharmacology, Biochemistry and Behavior Increased sociability and gene expression of oxytocin and its receptor in the brains of rats affected prenatally by valproic acid. Pharmacol. Biochem. Behav. 131, 42-50 https://doi.org/10.1016/j.pbb.2015.01.021

Svitok P., Senko T., Panakova Z., Olexova L., Krskova L., Okuliarova M., Zeman M. (2017): Prenatal exposure to angiotensin2 increases blood pressure and decreases salt sensitivity in rats. Clin. Exp. Hypertens. 39, 489-494
Sykes S. D., Pringle K. G., Zhou A., Gustaaf A. (2014): The balance between human maternal plasma angiotensin II and angiotensin 1-7 levels in early gestation pregnancy is influenced by fetal sex. J. Renin-Angiotensin-Aldosterone Syst. 15, 523-531 https://doi.org/10.1177/1470320313477174

Von Bohlen und Halbach O., Albrecht D. (2006): The CNS reninangiotensin system. Cell Tissue Res. 326, 599-616 https://doi.org/10.1007/s00441-006-0190-8

Voigt J. P., Hörtnagl H., Rex A., Van Hove L., Bader M., Fink H. (2005): Brain angiotensin and anxiety-related behavior: The transgenic rat TGR(ASrAOGEN)680. Brain Res. 1046, 145-156 https://doi.org/10.1016/j.brainres.2005.03.048

Xiao D., Dasgupta C., Li Y., Huang X., Zhang L. (2014): Perinatal Nicotine Exposure Increases Angiotensin II ReceptorMediated Vascular Contractility in Adult Offspring. PLoS One 9, e108161 https://doi.org/10.1371/journal.pone.0108161

Zeman M., Kršková L., Stebelová K., Vrabcová M. (2007): Physiological and behavioral changes induced by over-expressed renin-angiotensin system in rats. In: Collection Symposium Series. pp. 107-111, Prague https://doi.org/10.1135/css200709107

Zhuo J. L., Li X. C. (2011): Peptides New insights and perspectives on intrarenal renin-angiotensin system : Focus on intracrine / intracellular angiotensin II. Peptides 32, 1551-1565 https://doi.org/10.1016/j.peptides.2011.05.012

Received: January 19, 2017

Final version accepted: April 3, 2017

First published online: June 27, 2017 